\title{
An Investigation of Scaled-FLC Using PSO for Multi-area Power System Load Frequency Control
}

\author{
Aqeel S. Jaber ${ }^{1}$, A.Z. Ahmad ${ }^{1,2,}$ Ahmed N Abdalla ${ }^{1}$ \\ ${ }^{1}$ Faculty of Electrical and Electronics Engineering, University Malaysia Pahang, Pekan, Malaysia \\ ${ }^{2}$ Sustainable En.\& Power Elec. Res. (SuPER) Group, University Malaysia Pahang, Pekan, Malaysia \\ Email: aqe77el@yahoo.com, zaharin@ump.edu.my, ahmed@ump.edu.my
}

Received April, 2013

\begin{abstract}
Load Frequency Control (LFC) is one of power systems important requirements which maintain the zero steady-state errors in the frequency changing and restoring the natural frequency to its normal position. Many problems are subject to LFC such as suddenly large load or suddenly disconnecting generating unit by the protection device. In this paper, multi-area Frequency Control by using the combination of PSO and fuzzy logic control (FLC) technique. PSO optimization method is used to tuning the fuzzy controller input and output gains. Four of an interconnected electrical power system used as a testing the effectiveness of the proposed method compared to a conventional PI controller and scaled-fuzzy controller. The simulation result has been shown that the controller can generate the best dynamic response in multi-load conditions.
\end{abstract}

Keywords: Fuzzy Control; PSO; Load Frequency Control

\section{Introduction}

One of the major requirements in parallel operation of interconnected power systems is the Load Frequency Control (LFC) which is responsible for scheduled power transfers between the interconnected areas at any disturbance in the case of the connecting or disconnecting generating unit or suddenly large load. Various controllers have been used in different areas could not efficiently control the frequency and rather slow for the output response due to fact of non-linearity in system components [1-2], time invariant and governed by strong cross-couplings of the input variables. Therefore, the controllers have to be designed with taking into account the nonlinearities and disturbances.

Many of control methodologies have been suggested to solve LFC problem. Static Output Feedback gains and Linear Matrix Inequality are the most efficient and effective tool which stabilizes the system which used to calculate the gains of PID controller [3]. The Robust adaptive control also has been used to deal with the change in a system parametric [4]. Optimization techniques have been done to solve LFC, but they require information about the entire system rather than local information [5]. Other control approaches such as PID-ANN, PI-fuzzy and optimal control applied to LFC has been reported in [6]. Using genetic algorithm to scale of PI fuzzy controller in LFC has been reported in [7].
This paper presents the FLC using PI-fuzzy controllers. The proposed controller is tuned using PSO to obtain the controller gains in order to get an efficient fuzzy control on four of an interconnected electrical power system. This is a new approach to optimize the fuzzy controller that differentiates to other's methods. The simulation results are carried out in term frequency response for its damping under different load conditions and compared it to the effectiveness of proposed controllers with other controllers. Simulation results show that the undershot and settling times with the proposed controller are better and guarantees robust performance under a wide range of operating conditions.

\section{Theoretical Background}

Power systems have multi-variable and complex structures and consist of different control blocks and deal with nonlinear and/or non-minimum phase systems [8]. Power systems are divided into control areas connected by tie lines and all generators are supposed to constitute a coherent group in each control area.

\subsection{Load Frequency Control}

The aim of LFC is to maintain real power balance in the system through control of system frequency. Small changes in real power are mainly dependent on changes in rotor angle $\delta$ and, thus, the frequency $f$. whenever the 
real power demands changes, a frequency change occurs. However, the change in angle $\delta$ is caused by momentary change in generator speed. This frequency error is amplified, mixed and changed to a command signal which is sent to turbine governor. The governor operates to restore the balance between the input and output by changing the turbine output. This method is also referred as Megawatt frequency or Power-frequency (P-f) control [9].

\subsection{Fuzzy Logic}

According to many researchers, there are some reasons which present popularity of fuzzy logic control such as easily applied for most applications in industry. Besides, it can deal with intrinsic uncertainties by changing the controller parameters. On the other hand, their robustness and reliability make fuzzy controllers useful in solving a wide range of control problems [10]. The fuzzy controller for the single input, single output type of systems is shown in Figure 1 [7]. Fuzzy logic shows experience and preference through its membership functions. These functions have different shapes depending on system experts' experience [11].

\subsection{PSO Algorithm}

PSO was introduced by Eberhart and Kennedy as a new heuristic method $[12,13]$. PSO was inspired by the foodsearching behaviours of fish and their activities or a flock of birds. In D-dimensional search space. The best individual position of particle $i$ and the best position of the entire swarm are represented by

$$
\begin{aligned}
& v_{2}(t+1)=\omega v_{1}(t)+c_{1} n_{1}\left(p_{1}(t)-X_{1}(t)+c_{2} n_{2}(G(t)-\right. \\
& X_{1}(t) \\
& X_{l}(t+1)=X_{l}(t)+v_{1}(t+1)
\end{aligned}
$$

where:-

$P i=(p i 1, p i 2, \ldots, p i D)$ and $G=(g 1, g 2, \ldots, g D)$, respectively, $\omega$ is inertia weight parameter and $c 1, c 2$ is acceleration coefficients. In each iteration the particles will using eq. $1 \& 2$ to update their position $(x i)$ and velocity $\left(v_{i}\right)[12]$.

\section{Four Area LFC Model}

The net power $(\triangle P)$ due to disturbance $\left(\Delta P_{D}\right)$ is when the changes in power generation. Where the $\Delta P_{G}$ is described $\operatorname{as}(3)$.

$$
\Delta P^{\prime}=\Delta P_{g}-\Delta P_{b}
$$

This change will absorbed by changing in kinetic energy $\left(W_{k i n},\right)$ load consumption and export of power $\left(\Delta P_{\text {tie }}\right)$ so $\Delta P$ for $i_{t h}$ area is as follows;

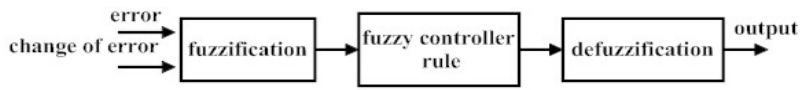

Figure 1. Fuzzy controller block diagram.

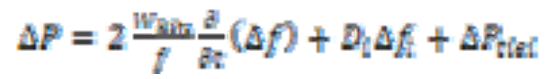

where, $D_{i}$ is power regulation and equal to $\Delta P / \Delta f$. By taking Laplace transformation

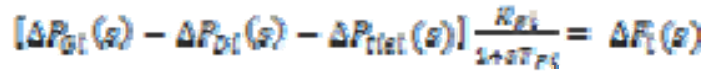

where, $\tau_{P L}=\frac{2 M}{f D e},(H)$ is inertia constant and $(f)$ is the frequency. If the line losses are neglected, the individual $\Delta P_{\text {tie } i j}$ can be written as

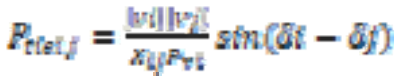

$$
\begin{aligned}
& P_{\text {trext }}=7_{i j} \int \Delta f_{i} d t-\int \Delta f_{i} d t
\end{aligned}
$$

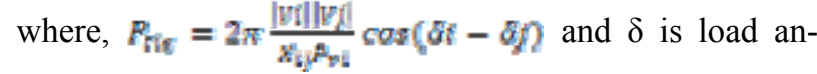
gle. Upon Laplace transforming (5), one gets

$$
\Delta R_{\text {tie }]}(\mathrm{s})=\frac{T_{11}}{\mathbb{I}}\left[\Delta \mathrm{F}_{\mathrm{B}}(\mathrm{s})-\Delta \mathrm{F}_{\mathrm{w}}(\mathrm{s})\right]
$$

The transfer of generator turbine (Gtf) is written by

$$
G_{i t}=\frac{a}{(1+a T C D(s+n T)}
$$

where, $T_{T}$ are turbine time constant and $T_{G}$ speed governor time constant. The parameters can be represented such in the Figure 2.

From Figure 2, the bias factor $(\mathrm{Bi})$ is suitable value can be computed as follows

$$
B_{1}=\frac{k}{R}+D_{1}
$$

ACEi, Ri are area control error, speed droop characteristic of area (i) respectively.

Figures $3 \& 4$, show $i^{\text {th }}$ area block diagram of and illustrate the tie line block diagram of interconnected power system [10].

Figure 4 shows the method of interconnection between four areas that have been used in this paper.

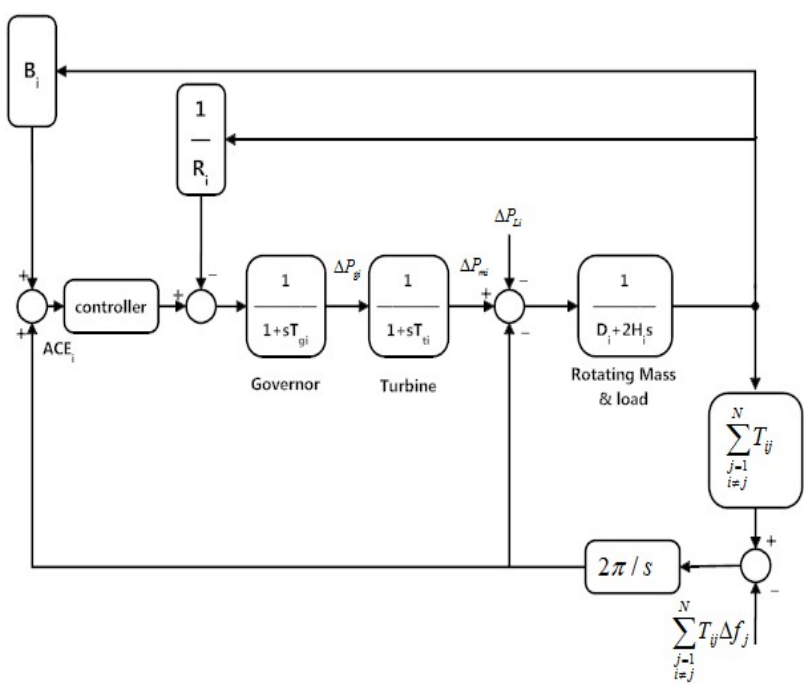

Figure 2. LFC Model for one area of system. 


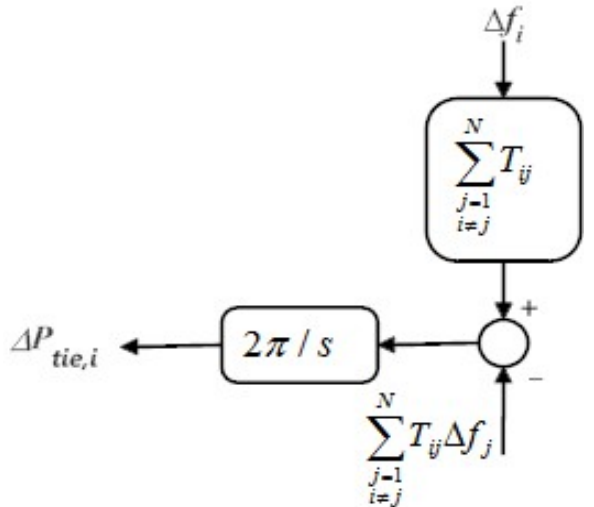

Figure 3. Model of tie-line power control area.

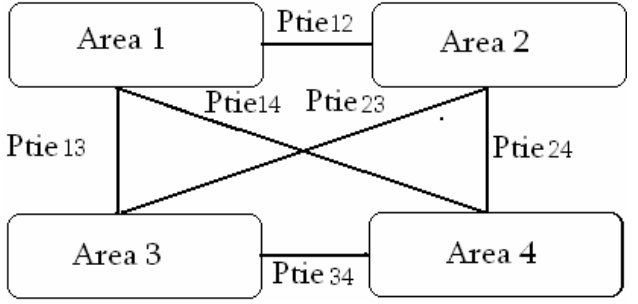

Figure 4. Four-area interconnection power system.

\section{Proposed Method}

The boundary of the membership functions that are adjusted based on expert in classical Fuzzy methods, person's experiences may be does not guarantee the systems' performance. The boundaries of the membership functions are tuned by PSO to select the best boundaries by finding suitable gains (scaled fuzzy parameters) for the inputs and output fuzzy controller. These gains obtain by three parameters Gin1, Gin2 and Gout that shown in Figure 5 are defined the uncertain range by PSO algorithms. The fuzzy rule has been designed as in Table 1 hat based on the number of membership function from the inputs and the output (as in Figure 7).The flow chart of PSO algorithm to optimize the scaled fuzzy parameters is shown in Figure 6. where:

MP: medium positive, SP: small positive, SN: small negative, $\mathrm{Z}$ : zero and $\mathrm{MN}$ : medium negative.

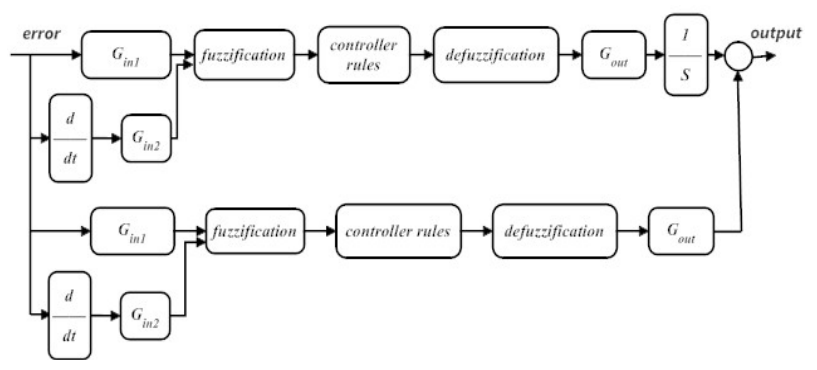

Figure 5. Scaled Fuzzy PI controller diagram.
Table 1. Fuzzy controller rules.

\begin{tabular}{cccccc}
\hline $\mathbf{e}_{/ \Delta \mathrm{e}}$ & $\mathbf{M P}$ & $\mathbf{S P}$ & $\mathbf{Z}$ & $\mathbf{S N}$ & $\mathbf{M N}$ \\
\hline $\mathbf{M P}$ & MP & SP & SP & $\mathrm{Z}$ & $\mathrm{Z}$ \\
$\mathbf{S p}$ & $\mathrm{SP}$ & $\mathrm{SP}$ & $\mathrm{Z}$ & $\mathrm{Z}$ & $\mathrm{NS}$ \\
$\mathbf{Z}$ & $\mathrm{SP}$ & $\mathrm{Z}$ & $\mathrm{Z}$ & $\mathrm{NS}$ & $\mathrm{NS}$ \\
$\mathbf{S N}$ & $\mathrm{Z}$ & $\mathrm{Z}$ & $\mathrm{NS}$ & $\mathrm{NS}$ & $\mathrm{MN}$ \\
$\mathbf{M N}$ & $\mathrm{Z}$ & $\mathrm{NS}$ & $\mathrm{NS}$ & $\mathrm{MN}$ & $\mathrm{MN}$
\end{tabular}

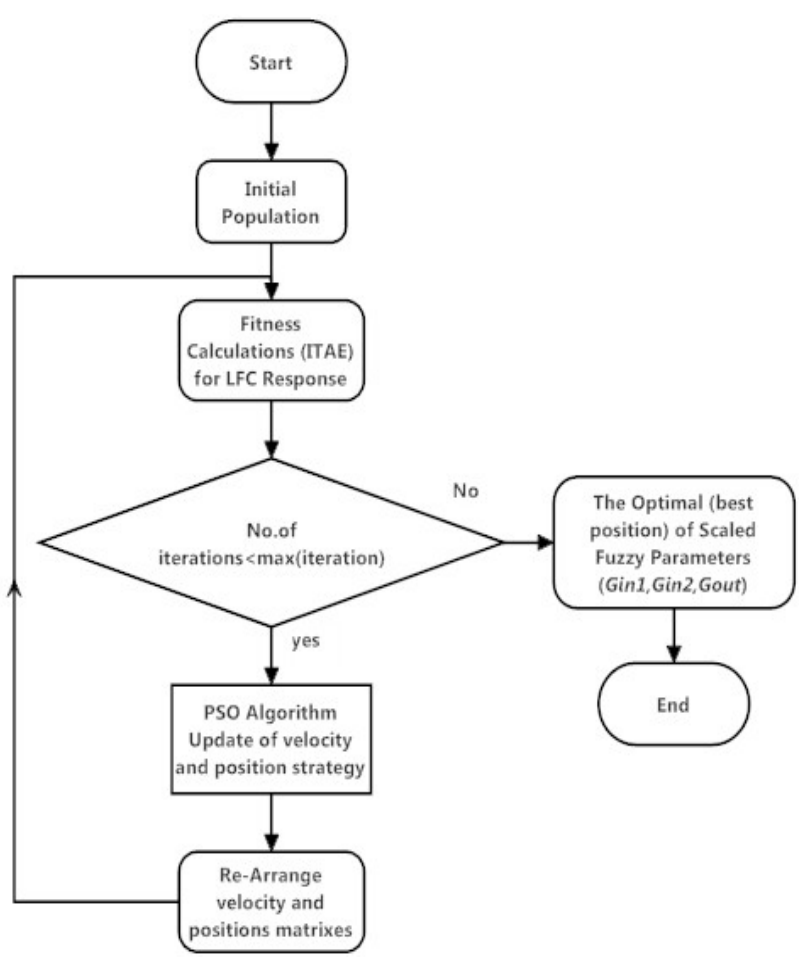

Figure 6. Optimizing fuzzy parameter using PSO.

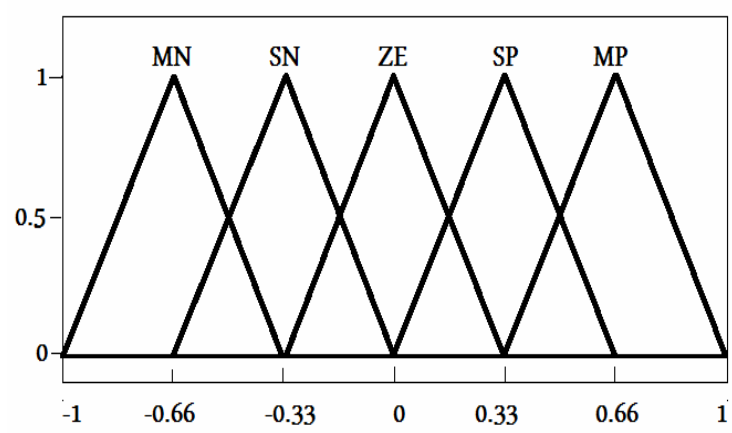

Figure 7. Membership function for input \& output of fuzzy controller.

\section{Result and Discussion}

The proposed method effectiveness was tested in order to investigate the system performance by using the MATLAB 7.1. Tables $2 \& 3$, list all system parameter and tie line parameter. 
The scaled fuzzy type controller was designed and compared with the classical fuzzy and PSO-PID for LFC under system uncertainties (controller robustness) in multi load conditions. The frequency response results are shown in Figure 8 and Figure 9 respectively.

The tie power response is shown if Figure $\mathbf{1 0}$ and Figure 11 respectively.

Table 4, show the optimum $K P$ and $K I$ for PI controllers parameters using PSO, and the optimum values of the scaled fuzzy parameters that are computed by using PSO algorithms is shown in Table 5.

Table 2. Four area model parameters.

\begin{tabular}{ccccccc}
\hline Area & $\mathrm{R}$ & $\mathrm{T}_{\mathrm{G}}$ & $\mathrm{T}_{\mathrm{T}}$ & $\mathrm{T}_{\mathrm{P}}$ & $\mathrm{K}_{\mathrm{P}}$ & $\mathrm{B}$ \\
\hline 1 & 2.4 & 0.08 & 0.030 & 20.08 & 120 & 0.401 \\
2 & 2.1 & 0.091 & 0.025 & 17.24 & 111 & 0.3 \\
3 & 2.9 & 0.072 & 0.044 & 22.97 & 135 & 0.48 \\
4 & 1.995 & 0.044 & 0.044 & 53.19 & 106 & 0.391 \\
\hline
\end{tabular}

Table 3. Tie Line Parameters.

\begin{tabular}{cccccc}
\hline T12 & T13 & T14 & T23 & T24 & 34 \\
\hline 0.425 & 0.5 & 0.4 & 0.455 & 0.523 & 0.6 \\
\hline
\end{tabular}

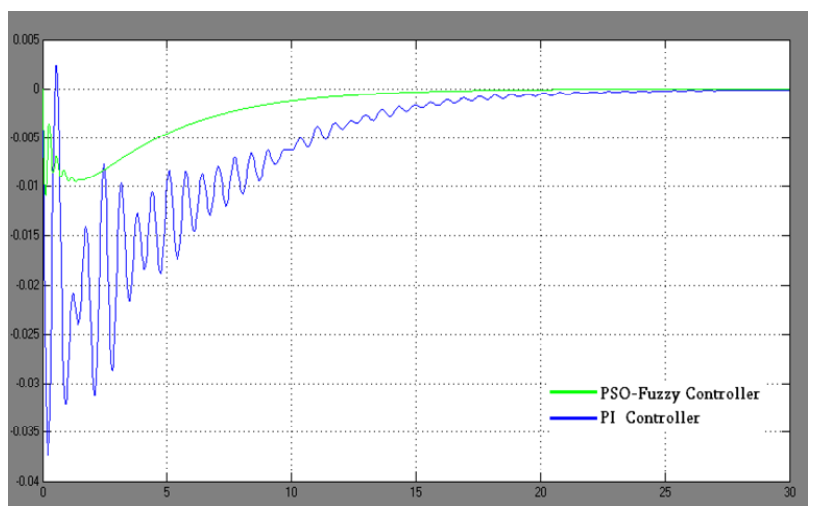

Figure 8. Frequency deviations of $30 \%$ load change.

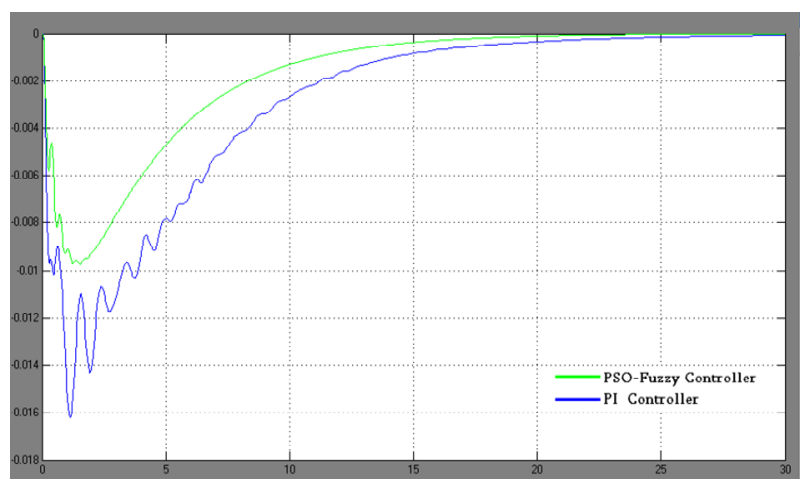

Figure 9. Frequency deviations of $50 \%$ load change.

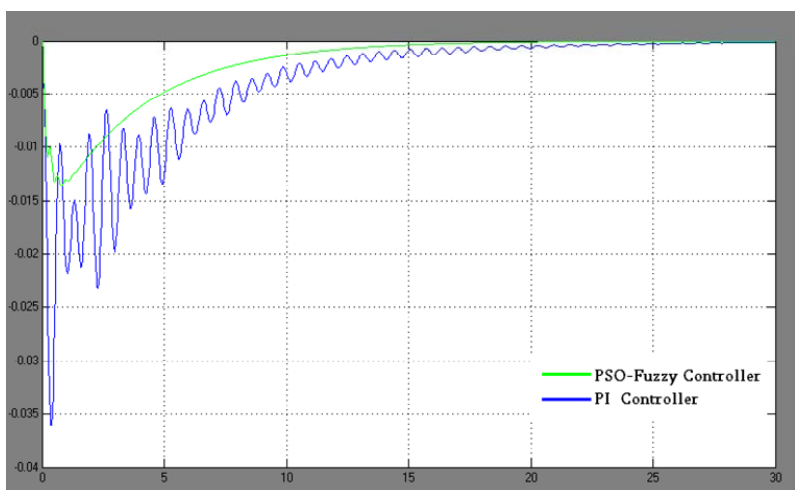

Figure 10. Tie power transfer of $3 \%$ load change.

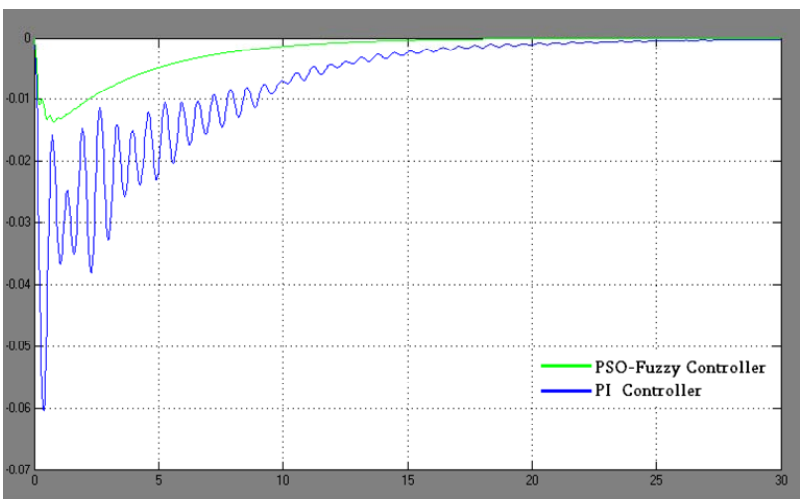

Figure 11. Tie power transfer of $5 \%$ load change.

Tabl4. PI controller values.

\begin{tabular}{ccc}
\hline Area & $\boldsymbol{K p}$ & $\boldsymbol{K i}$ \\
\hline 1 & 0.51 & 0.631 \\
2 & 0.432 & 0.551 \\
3 & 0.552 & 0.681 \\
4 & 0.601 & 0.61 \\
\hline
\end{tabular}

Table 5. Scaled Fuzzy Parameters.

\begin{tabular}{cccc}
\hline Area & Gin1 & Gin2 & Gout \\
\hline 1 & 0.138 & 0.074 & 0.0114 \\
2 & 0.129 & 0.057 & 0.0960 \\
3 & 0.139 & 0.0234 & 0.1181 \\
4 & 0.039 & 0.128 & 0.1172 \\
\hline
\end{tabular}

Table 6 shows for the frequency deviation of peak under shoot $\&$ and settling time for scaled fuzzy-PI controller and conventional PI controller for each interconnected power system area.

where: $\mathrm{P}_{\mathrm{US}}$ : Peak undershoot, St (s): Settling times (s), L.Ch: \%load change 
Table 6. Frequency Response Comparison For Scaled Fuzzy-PI Controller And Conventional PI Controller.

\begin{tabular}{ccccc}
\hline \multirow{2}{*}{ L.Ch } & \multicolumn{2}{c}{ PI controller } & \multicolumn{2}{c}{ PSO fuzzy controller } \\
\cline { 2 - 5 } & $\mathrm{P}_{\mathrm{US}}$ & $\mathrm{St}(\mathrm{s})$ & $\mathrm{P}_{\mathrm{US}}$ & S.t (s) \\
\hline 1 & 0.0818 & 21.2 & 0.0045 & 14.23 \\
2 & 0.0233 & 23.1 & 0.0081 & 14.97 \\
3 & 0.0361 & 23.7 & 0.0132 & 15.12 \\
4 & 0.0472 & 24.5 & 0.0178 & 15.43 \\
5 & 0.0605 & 24.81 & 0.0227 & 15.91 \\
\hline
\end{tabular}

Table 7. Power transfer response Comparison of scaled fuzzy-PI controller and conventional PI controller.

\begin{tabular}{ccccc}
\hline \multirow{2}{*}{ L.Ch } & \multicolumn{2}{c}{ PI controller } & \multicolumn{2}{c}{ PSO fuzzy controller } \\
\cline { 2 - 5 } & $\mathrm{P}_{\mathrm{US}}{ }^{*} 10^{\wedge}-3$ & $\mathrm{St}(\mathrm{s})$ & $\mathrm{P}_{\mathrm{US}}$ & $\mathrm{St}(\mathrm{s})$ \\
\hline 1 & 5.342 & 22.4 & 3.321 & 17.14 \\
2 & 10.938 & 23.2 & 6.712 & 18.52 \\
3 & 16.311 & 23.7 & 9.131 & 18.79 \\
4 & 22.331 & 23.9 & 12.342 & 19.31 \\
5 & 27.211 & 24.8 & 16.201 & 20.54 \\
\hline
\end{tabular}

Table 7 shows for the total power transfer deviation of peak under shoot $\&$ and settling time for scaled fuzzy-PI controller and conventional PI controller for each interconnected power system area.

The robustness of the proposed method performance is demonstrated based on ITAE that is under step change in the different demands as

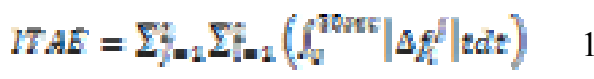

Finally, from tables $(6,7)$ and figures (8 to 11) of step change, the scaled Fuzzy controller has better performance than the optimized PI controller at all operating conditions. Therefore, the performance comparison between both controllers indicates that the frequency response of the proposed method has smaller undershoot and shorter in settling time with respect to PI controller.

\section{Conclusions}

This paper introduces PSO-FLC to improve the performance of four-area power system and the linearization in errors is considered as parametric uncertainties. Each area consists of the turbine, governor and power system which modelled by first-order transfer functions. In addition, PSO was used to adjust the input and the output of FLC memberships. Simulation results proved that the proposed scaled FLC has obtained fast response and less undershoots compared to conventional PI controller.

\section{REFERENCES}

[1] Y. Wang, R. Zhou and C. Wen, "Robust Load-frequency Controller Design for Power Systems," Generation, Transmission and, Vol. 140, No. 1, 1993.

[2] E. Çam and İ. Kocaarslan, "Load Frequency Control in Two Area Power Systems using Fuzzy Logic Controller," Energy Conversion and Management, Vol. 46, No. 2, 2005, pp. 233-243. doi:10.1016/j.enconman.2004.02.022

[3] A. A. Ghany, "Design of Static Output Feedback PID controller via ILMI method for a Power System Stabilizer," Power System Conference, MEPCON, 2008.

[4] A. Stankovic, "On Robust Control Analysis and Design for Load Frequency Regulation," Power Systems, IEEE, Vol. 13, No. 2, 1998, pp. 449-455. doi:10.1109/59.667367

[5] K. Parmar, S. Majhi and D. Kothari, "Multi-area Load Frequency Control in a Power System using Optimal Output Feedback Method,"(PEDES) \& 2010 Power, 2010.

[6] C. Chang and W. Fu, "Area Load Frequency Control using Fuzzy Gain Scheduling of PI Controllers," Electric Power Systems Research, 1997.

\section{doi:10.1016/S0378-7796(96)01199-6}

[7] S. Broujeni, S. Hemmati and H. Fayazi, "Load Frequency Control in Multi Area Electric Power System using Genetic Scaled Fuzzy Logic,” Int. J. Phys. Sci, 2011.

[8] J. Hertz, A. Krogh and R. Palmer, "Introduction to the Theory of Neural Computation," 1991.

[9] H. Saadat, Power System Analysis, Mcgraw-Hill, 2005.

[10] T. W.Yang, R. Zhang and C. Zhang, "Research of Realizing PID Controller Based On FPGA," Microcomputer Information, 2005, pp. 2-11.

[11] K Tomsovic "Fuzzy," in International Conference On Intelligent System Application, 1999.

[12] J. Kennedy and R. Eberhart, "Particle Swarm Optimization," Neural Networks, 1995. Proceedings, pp. 2-6.

[13] A. Jaber, A. Ahmad and A. Abdalla, "Advance Two-Area Load Frequency Control Using Particle Swarm Optimization Scaled Fuzzy Logic," Advanced Materials Research, Vol. 622-623, 2013, pp. 80-85. 